\title{
Can body traits, other than wings, reflect the flight ability of Triatominae bugs?
}

\author{
María Laura Hernández ${ }^{[1]}$, Jean Pierre Dujardin ${ }^{[2]}$ David Eladio Gorla ${ }^{[1],[3]}$ \\ and Silvia Susana Catalá ${ }^{[1]}$
}

[1]. Centro Regional de Investigaciones Científicas y Transferencia Tecnológica, Anillaco, La Rioja, Argentina. [2]. Unité Mixte de Recherche 177-Interactions Hôte-Vecteur-Parasite-Enrironnement dans les Maladies Tropicales Négligées dues aux Trypanosomatidés, Institut de Recherches pour le Développement, Montpellier, France. [3]. Instituto Multidisciplinario de Biología Vegetal, Córdoba, Argentina.

\begin{abstract}
Introduction: Insects of the subfamily Triatominae are vectors of Trypanosoma cruzi, the Chagas disease parasite, and their flying behavior has epidemiological importance. The flying capacity is strikingly different across and within Triatominae species, as well as between sexes or individuals. Many Triatoma infestans individuals have wings but no flying muscles. In other Triatominae species, no clear relationships were found between wing length and flying behavior. If wing presence or size is not reflective of the flying behavior, which other parts of the body could be considered as reliable markers of this important function? Methods: The genus Mepraia has exceptional characteristics with invariably wingless females and wingless or winged males. We calculated the porous surface exposed to odorant molecules to estimate the olfactory capacity of Mepraia spinolai. The head shape and thorax size were estimated using the geometric morphometric approach and traditional morphometric techniques, respectively. Results: Alary polymorphism in M. spinolai was significantly associated with consistent modification of the thorax size, head shape, and notable change in the estimated olfactory capacity. The macropterous individuals had a larger olfactory surface and thorax size and significantly different head shape compared to those of the micropterous individuals. Conclusions: We concluded that these structural changes could be associated with the flying potential of Triatominae. Thus, morphological attributes not found on wings could help determine the likely flying potential of the bugs.
\end{abstract}

Keywords: Triatominae. Alary polymorphism. Olfactory sensilla. Flight ability. Mepraia spinolai.

\section{INTRODUCTION}

Dispersal capacity by flight is an important feature in insects and plays a key role in evolutionary processes ${ }^{(1)(2)}$. Several insect species are polymorphic in their dispersive capacity, by having a discontinuous variation either in their wing length or the flight muscle $\operatorname{mass}^{(3)(4)(5)(6)}$. The loss or reduction of wings in pterygote insects is not fortuitous, but is related to environmental and geographical causes such as gender, metamorphosis types, taxa, and reproductive strategies.

Polymorphism in wing size is common among different insect taxa ${ }^{(1)(4)(5)(7)}$. In some cases, the loss or reduction of wings occurs in a single sex, mainly in females, since it allows them to divert the energy used for wings and flight muscles to the production of eggs, which has a high energy demand. Mate location can be an important factor for the retention of wings or flight capacity and is more frequent in males. The flightless

Corresponding author: Dra María Laura Hernández. CRILAR-CONICET. Mendoza \& Entre Ríos s/n (5301) Anillaco, La Rioja, Argentina.

Phone: 5403 827-494251; Fax: 5403 827-494231

e-mail: mlhernandez@crilar-conicet.gob.ar

Received 24 July 2015

Accepted 16 September 2015 frequency is more common in paurometabolous insects such as Triatominae (Hemiptera, Reduviidae) than hemimetabolous or holometabolous insects, since in the former, nymphs and adults occupy the same environment. Triatominae insects are vectors of Trypanosoma cruzi, the etiological agent of Chagas disease. Currently, the dispersal of these insects continues to remain an epidemiologically important issue, because of its connection with the geographical distribution of the species and the spread of the disease ${ }^{(8)}$. All adult triatomines are winged insects, except for females and some male specimens of two species, Mepraia spinolai and Mepraia gajardo $i^{(9)}$. The Mepraia genus is endemic to the arid and semiarid regions of north and central Chile and is the only one within Triatominae to present a well-marked alary polymorphism. Hence, this genus could be used as a model to analyze the morphological adaptations associated with the development of wings and flight capacity in Triatominae.

Mepraia spinolai lives in the arid regions of north and central Chile and in some coastal islands ${ }^{(10)}$. It has been found to be associated with stony areas and resting sites of different mammals such as foxes, rabbits, hares, rodents, marsupials, and domestic animals ${ }^{(11)}$ and is occasionally associated with terrestrial bromeliads (e.g., Puya sp.) ${ }^{(12)}$. Females of M. spinolai are invariably wingless, whereas males might be wingless or winged, with wings having normal length or extending up to $2 \mathrm{~mm}$ beyond the terminalia. The wingless forms need to be 
strictly termed micropterous, because tiny wingpads are present both on the meso- and metathoracic segments ${ }^{(13)}$. Similarly, the two forms of winged males are more correctly described as submacropterous and macropterous because, although the long-winged macropterous forms have similar wing shape and venation to that of other species of Triatominae, the normallength submacropterous wings sometimes show slightly truncated venation of the membrane both of the meso- and metathoracic wings ${ }^{(11)}$. Campos et al. ${ }^{(14)}$ detected a new wing phenotype in Mepraia with vestigial wings and shape features intermediate between that of M. spinolai and M. gajardoi, associated with a coastal area in Northern Chile.

Shortening of wings has been observed in laboratory individuals and/or geographical populations of Triatominae ${ }^{(15)(16)(17)(18)}$; however, whether this modifies their ability to fly is not known.

The habitat where an insect develops is known to cause behavioral, physiological, and morphological variations that might affect the dispersal capacity and influence the selection of a new target habitat ${ }^{(19)(20)(21)}$. The organs where these changes have been quantitatively detected are wings, head, thorax, and antennae ${ }^{(22)(23)(24)(25)(26)(27)(28)(29)(30)}$. Geometric morphometry allows decomposition of the variation resulting from the physiology of an individual (size) from that of the genetic component (variation of shape) ${ }^{(31)}$. In addition, because triatomine insects occupy a wide variety of habitats, their sensory system displays different specializations reflected by their antennal phenotype ${ }^{(32)}$. Therefore, both the geometric morphometry of the head and the analysis of antennal phenotypes are good tools to identify individuals from environmentally different sites ${ }^{(26)(27)(33)(34)}$ and are very useful for analyzing the changes related to the acquisition of wings such as in the transition from nymph to adult ${ }^{(26)(35)}$, or in the case of wingless insects, where geometric morphometry of wings cannot be used. In Mepraia spp., a marked variability was found in the antennal phenotype related to the wing condition, resulting in a greater number and increased length of olfactory sensilla on the pedicel in macropterous males than in micropterous males ${ }^{(36)}$.

Earlier observations on many Triatominae species (Catalá, unpublished) allow us to hypothesize that the head and thorax undergo significant modifications related to changes in the wings and could be indicators of their ability to fly. Moreover, the presence of wings might be associated with the modification of other variables related to flight such as antennal olfactory receptors ${ }^{(35)}$.

Several studies have attempted to characterize the flight ability of Triatominae, but ethical issues prevent experiments from being conducted in the natural habitat where these vectors develop and live. Markers proposed to detect insects with greater flight ability proved of very limited applicability and did not allow comparison between species. Studies determining the maximum distance reached by flight in Triatoma infestans do not reflect the actual ecological and/or physiological conditions to which the insects are subjected ${ }^{(37)(38)}$. Physiological indicators of flight potential, such as the weight/length index ${ }^{(39)(40)(41)}$ and the qualitative and quantitative conditions of the thoracic muscles ${ }^{(42)(43)(44)(45)}$, have limited applicability since they reflect a particular physiological state in the life history of the insect. Focusing only on the wing traits might be misleading, because old laboratory colonies of $T$. infestans ${ }^{(46)}$ - as well as a proportion of field-collected specimens ${ }^{(45)(47)(48)}$ - have been shown to have wings but no thoracic muscles.

We think that other fixed characters of adults, which are not modified during the adult life, might be useful indicators for comparative studies of Triatominae species and, with the addition of particular characteristics as weight/length ratio and thorax muscle mass, could allow the determination of population differences within a species. During the final molt and the acquisition of wings, morphological changes related to newly acquired reproduction and flight activities are known to occur. Changes in thorax, wings, head, and antennas in the nymph-adult transition as well as in insects with wing polymorphism ${ }^{(22)(23)(35)}$ would provide evidence of the ability of insect flight. Therefore, in order to infer flight potential in T. cruzi insect vectors, identifying quantitative markers not only those recorded from the wings themselves is necessary. In this regard, we examined the head, thorax, and antennal olfactory sensilla and compared them according to the presence or absence of wings in M. spinolai. Such markers might be useful in predicting the flight ability in more domestic triatomine bugs, especially within the context of house reinfestation studies.

\section{METHODS}

\section{Insects}

Sixteen micropterous males, 7 winged males ( 5 submacropterous and 2 macropterous), and 28 micropterous females of M. spinolai were used. A group of $4 \mathrm{fifth}$ instar nymphs of the same species was used for thorax width measurements. Insects used in this study are the same specimens used by Moreno et al. ${ }^{(36)}$.

Early analyses on $M$. spinolai were conducted considering the three male wing conditions-micropterous, submacropterous, and macropterous. Since submacropterous and macropterous insects did not show substantial differences in their antennal phenotype and size and shape of heads and because macropterous insects are infrequent ${ }^{(49)}(5 \%$ of adult males), we grouped M. spinolai males into two categories: macropterous males (which included macropterous and submacropterous) and micropterous males.

\section{Geometric morphometrics}

The heads were separated at the collar and mounted on a pin attached to a metal bracket. Photographs of the ventral surface of the heads were obtained using a Kodak C613 digital camera (6.2 MP) and a stereomicroscope (10× magnification). Ten type II landmarks were selected on the image of the ventral side of the adult heads (Figure 1). Average landmarks on both the sides of the head (5 landmarks) were used to reduce the intraindividual variation and digitizing errors. The shape variables were obtained using generalized procrustes analysis and the subsequent projection into a Euclidean space by computing partial warps $(\mathrm{PWs})^{(50)}$. Partial warps describe shape variation 


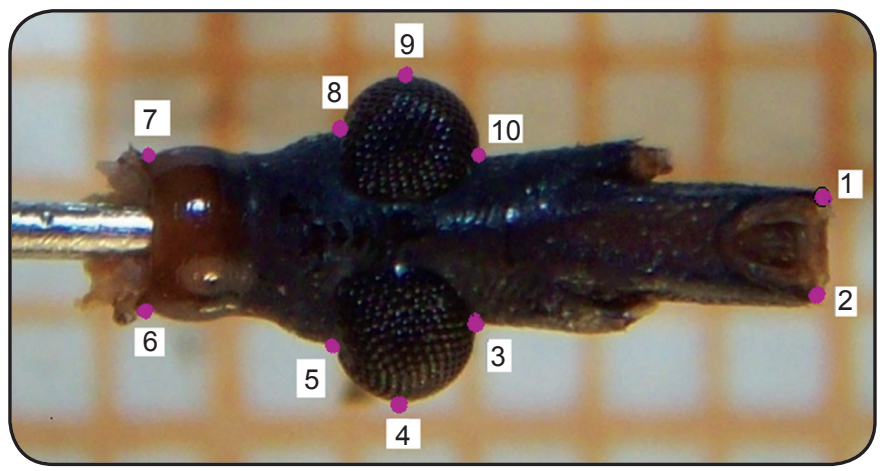

FIGURE 1 - Points of reference (landmarks) measured as coordinates of the heads in Mepraia spinolai (Porter). The numbers indicate the order of landmark capture.

as deviations from the average landmark configuration. For head size comparison, the centroid size (CS) was used; it is derived from the coordinates data. It is defined as the square root of the sum of the squared distances between the centroid of the landmark configuration and each individual landmark ${ }^{(31)}$. The variance of head shape was determined using the metric disparity (MD) index. This index provides a single value measuring the variety of forms in a sample; it is based on the Euclidean distances of each form with the consensus one ${ }^{(51)}$. Statistical comparisons for head shape, CS, and MD were made using non-parametric permutation-based tests $(5,000$ cycles $)$.

\section{Thorax width and wing length}

Thorax width, defined as the distance between humeri of the fifth instar nymphs and adults, and the wing length of M. spinolai adults were measured using an ocular micrometer on a Leica MZ12 stereomicroscope. For micropterous adults, the length of wing pads was considered as the basis for comparison of wing length. Since a portion of the wing chorion had been cut for previous analysis by other researchers, wing measurement was obtained from the intersection between the radial and median veins at the most distal edge of the wing. Thorax width and wing length were used as a proxy of the thoracic muscular competence. Although the thoracic cavity might be empty, it is useful as an indicator of the maximum amount of muscle mass that it might contain.

\section{Antennal olfactory sensilla}

Thin-walled trichoids (THs) are involved in the remote perception of volatiles, and thus in flight activity for the identification of habitats and/or hosts. These receptors have greater length in winged male adults of Mepraia sp. than in micropterous males and females and adults of other triatomine species $^{(36)}$. By using these previous data on length and number of TH sensilla, and knowing that pores are uniformly distributed over them ${ }^{(52)}$ (Catalá, unpublished), we calculated the porous surface exposed to odorant molecules. For the purposes of this study, we defined the olfactory estimated capacity (OEC) as the number of thin-walled trichoids on antennal pedicel
$(\mathrm{PTH}) \times$ average length of $\mathrm{TH}$ in microns $(\mu)$ according to Moreno et al. ${ }^{(36)}$.

The OEC between insect groups was compared using analysis of variance (ANOVA).

\section{Data collection and analysis}

For the digitization of landmarks, the analysis of morphometric data and multivariate analysis with antennal variables, we used the CLIC 97 package ${ }^{(53)}$. In addition, MorphoJ $1.05 \mathrm{f}^{(54)}$ was used for the analysis and graphical representation of the variations in the conformation of heads. The ANOVA statistics was performed using the Statistica package ${ }^{(55)}$.

\section{RESULTS}

Alary polymorphism in M. spinolai was significantly associated with consistent modification in the thorax size, head shape, and a notable change in the OEC. Below, we describe the results obtained for each structure analyzed.

\section{Head}

The head shape analysis (performed using 6 principal components, representing $92 \%$ of total shape variance) showed that all 3 groups (macropterous and micropterous males, and females) had statistically different head shapes $(p<0.0001)$. Because of the strong sexual size dimorphism in our data, a consistent allometric effect was recorded in the shape-based discrimination of the groups ( $55 \%$ for the first canonical factors). Micro- and macropterous males showed significant $(\mathrm{p}<0.05)$ allometry-free differences in head shape. The main changes affecting head shape was the difference in the outer distance between the eyes and the anteocular distance. The distance between eyes increased with the development of wings, being larger in macropterous males than in micropterous males and smaller in females. In contrast, the anteocular distance decreased in macropterous males and was significantly larger in females. The anteocular distance in micropterous males was intermediate between macropterous males and females. Landmarks 3, 4, 9, and 10 (related to the distance between eyes) and 1 and 2 (related to anteocular distance) were those that showed major displacements in comparison between groups (Figure 2).

Mepraia spinolai micropterous males showed the largest MD of head shape, which was significantly larger $(p<0.05)$ than that of macropterous males. Females showed lower MD than that in micropterous males, although not significantly different (Table 1).

The CS of heads was not significantly different between M. spinolai males with different wing conditions ( $p>0.05$ ). Sexual dimorphism of head size was detected; CS of females was larger than that of males (Table 1).

\section{Thorax and wing length}

The fifth instar nymphs showed lower humeral distance than adults (females and both male phenotypes). The thorax width was larger $(p<0.05)$ in macropterous than in micropterous males. The thorax width was significantly lower in females 

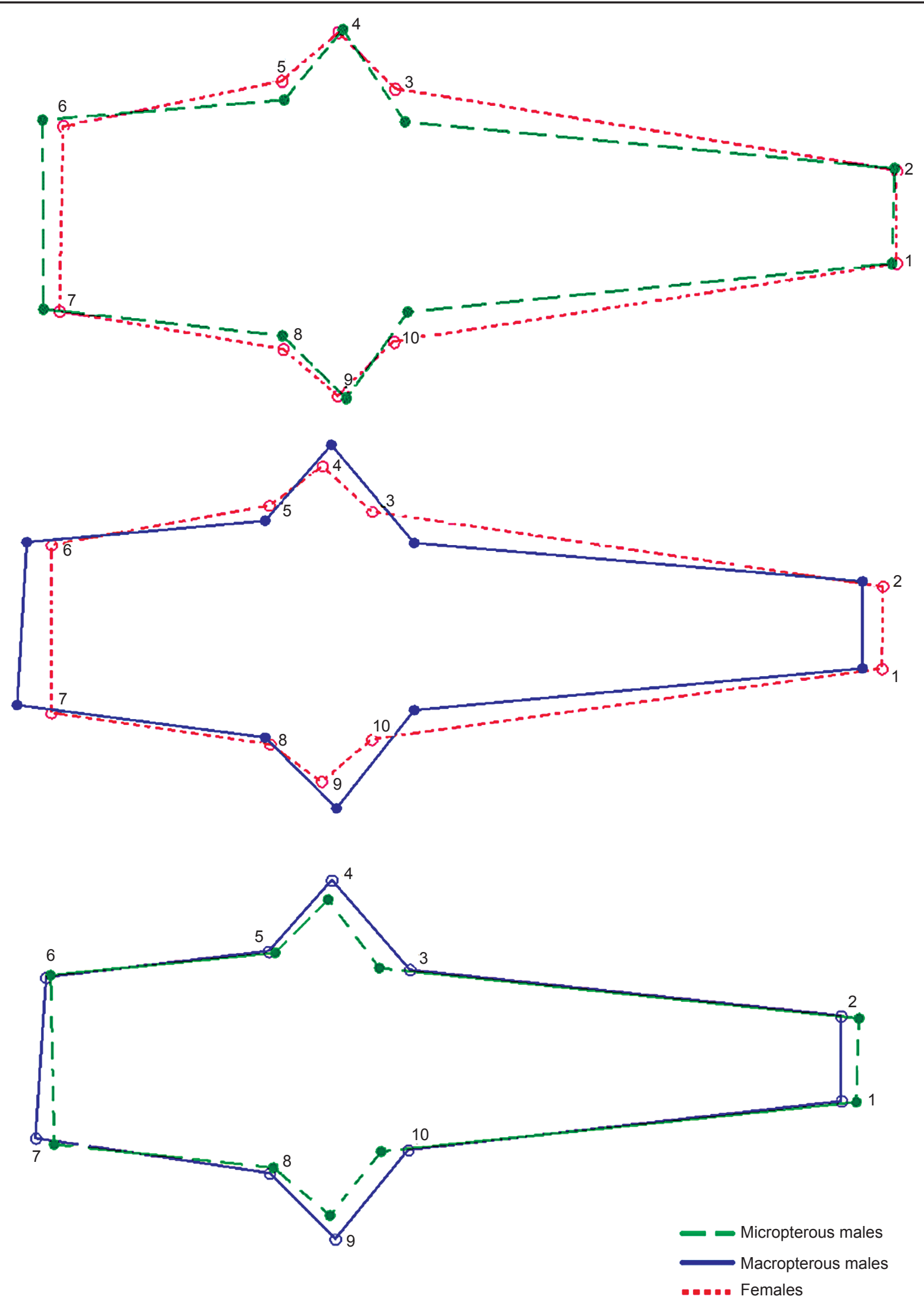

FIGURE 2 - Variation of adult head shape of Mepraia spinolai (Porter) and displacement of the landmarks of different groups. Mahalanobis distances between groups: female macropterous male, 13.75; female-micropterous male, 7.36; micropterous male-macropterous male, 12.73 . $p<0.01$ by nonparametric permutation-based tests $(5,000$ cycles $)$. 
TABLE 1 - Characteristics of the head and wings of adults of Mepraia spinolai having different wing conditions.

\begin{tabular}{|c|c|c|c|c|}
\hline Sex/wing conditions & Number of specimens & CS heads & MD heads & Wing length \\
\hline Male macropterous & 7 & $288.13^{*}$ & $0.000220^{*}$ & $9.10(1.48)^{*}$ \\
\hline Male micropterous & 16 & $286.28 *$ & $0.000314^{* *}$ & $1.13(0.07)^{* *}$ \\
\hline Females & 28 & $325.38 * *$ & $0.000260 * *$ & $1.31(0.07)^{* *}$ \\
\hline
\end{tabular}

CS: Centroid size of the head (median); MD: metric disparity of head shape. *;**Equal amounts of asterisks means that there are no statistically significant differences between groups $(\mathrm{p}<0.05)$ by non-parametric permutation-based tests $(5,000$ cycles $)$.

than in males. The thorax width (humeral distance) increases with wing length ( $r=0.82, \mathrm{p}<0.05$; Figure 3 ). The wing pad length of females and micropterous males did not differ, although it was different from the wing length of macropterous males (Table 1).

\section{Antennal olfactory sensilla}

The OEC of the TH sensilla of the pedicel increased by $92.6 \%$ in macropterous males of $M$. spinolai than in micropterous males. Sexual dimorphism of this variable was observed, confirming that, even in micropterous males, OEC is greater than that in females ( $p<0.05$; Figure 4).

\section{DISCUSSION}

In Mepraia spinolai, the alary polymorphism was associated with other body attributes: I) the OEC, II) thorax size, and III) head shape. We believe that these changes are morphological attributes probably related to the flying potential of Triatominae. Winged aphids (Hemiptera) exhibit stronger sclerotization of the head and thorax, further development of the eyes and ocelli, longer antennae, and more rhinaria, which have an olfactory function ${ }^{(56)(57)(58)}$. They are also equipped with an elaborated

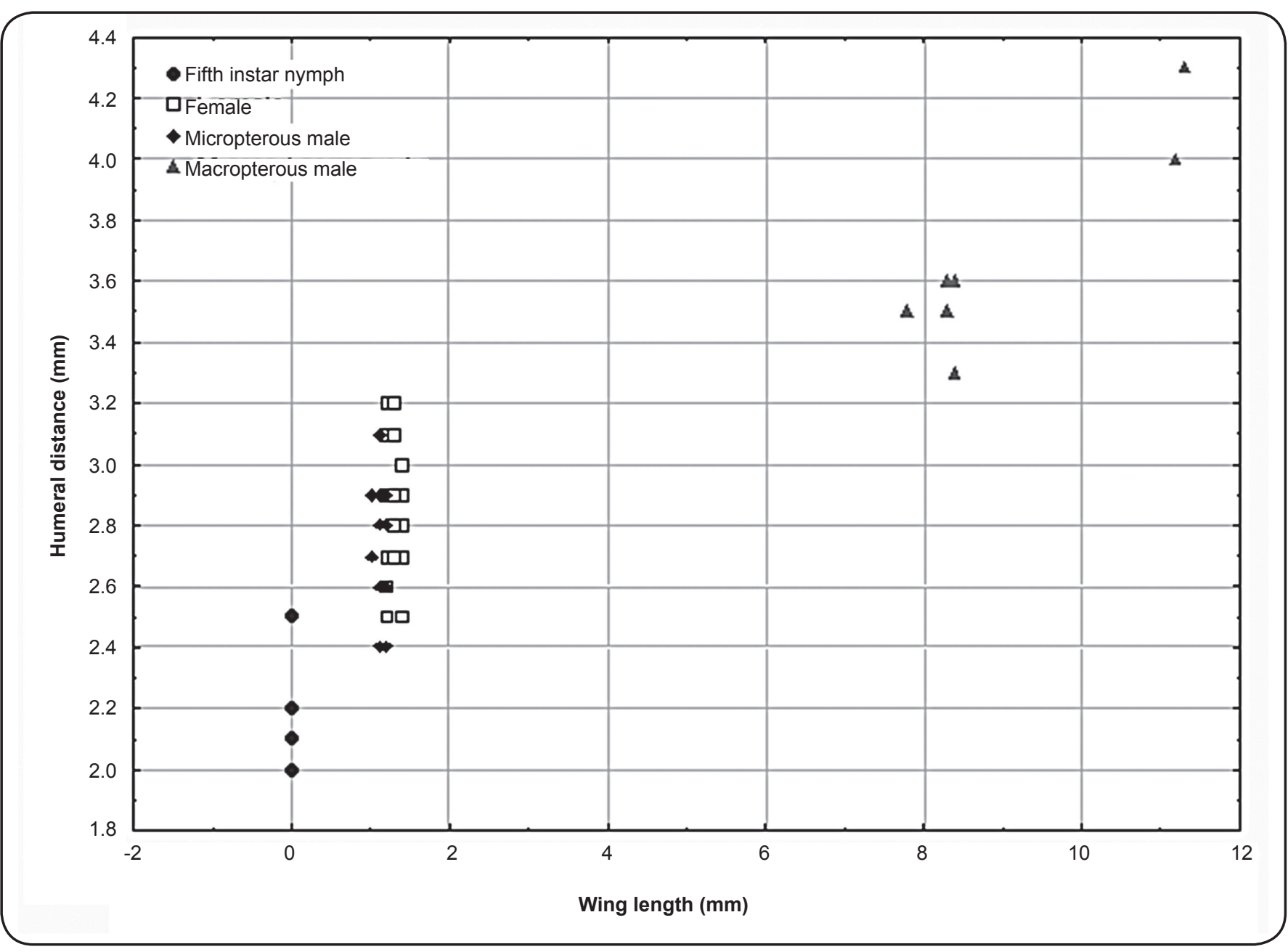

FIGURE 3 - Relationship between wing length and humeral distance ( $\mathrm{mm}$ ) of adults with different wing conditions and fifth instar nymphs of Mepraia spinolai (Porter). $\mathbf{R}=0.82, \mathbf{p}<0.05$. 


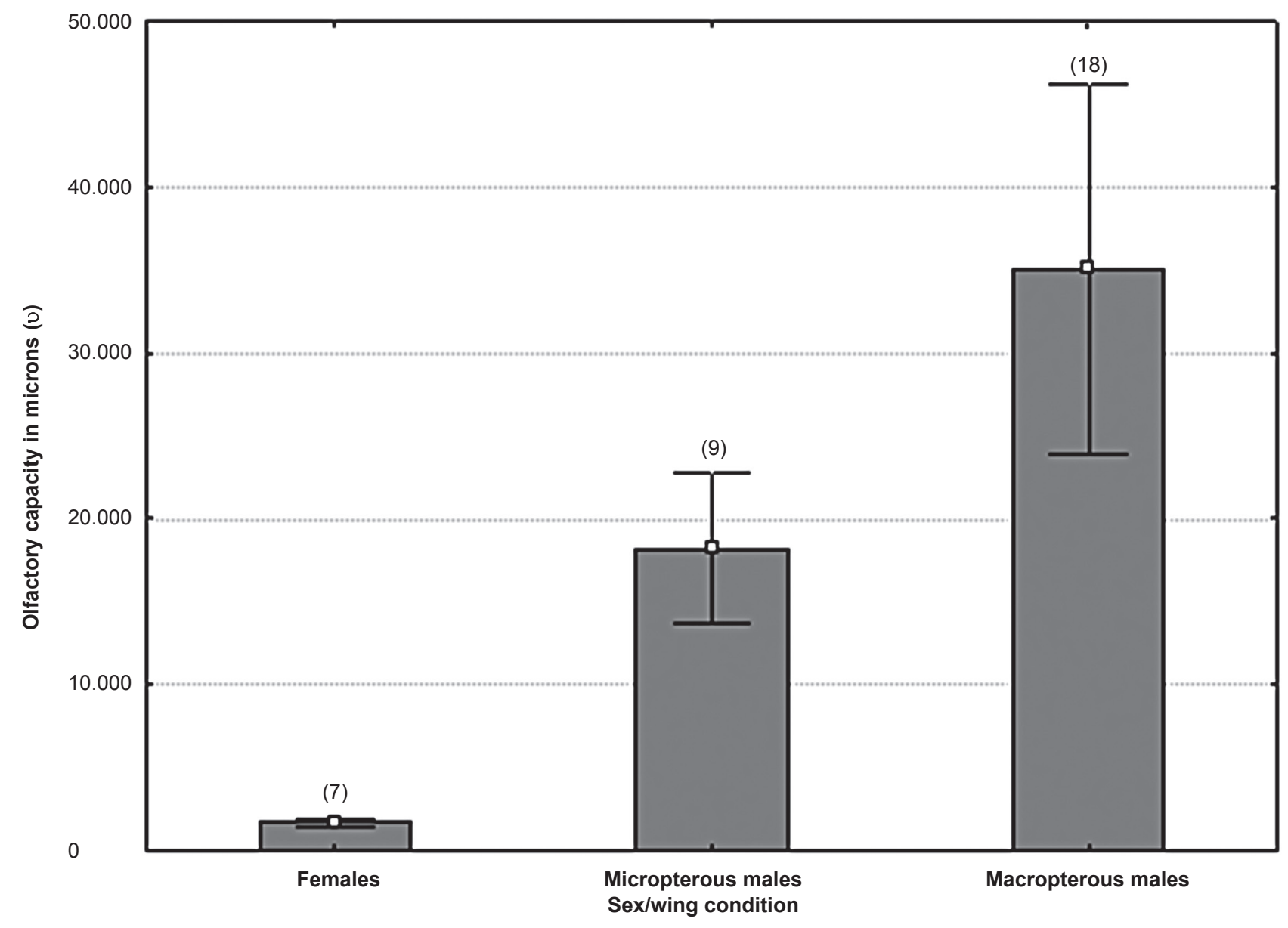

FIGURE 4 - Olfactory estimated capacity of adult Mepraia spinolai (Porter) with different wing conditions. OEC (in microns) $=$ PTH number $\times$ PTH average length $(\mu)$. The differences between groups are statistically significant $(\mathbf{p}<\mathbf{0 . 0 5})$. OEC: olfactory estimated capacity; PTH: thin-walled trichoids on the pedicel. M: males; F: females.

sensory system to search for host plants and show greater resistance to fasting than their wingless counterparts ${ }^{(59)(60)}$.

The ability to fly has obvious advantages in insects that need to disperse rapidly to remote distances, although the presence of wings does not guarantee flight. The dispersal behavior of insects is known to depend on multiple factors (local landscape conditions, intraspecific competition by limited food resources, mating, etc.) and can be highly variable even among individuals of the same species ${ }^{(61)(62)}$. Larger wing length does not always suggest greater flight ability. Almeida et al. ${ }^{(63)}$ found that the hybrid between Triatoma sherlocki (short wings, no fliers) and Triatoma juazeirensis (wings that reach the seventh or eighth urostergite, fliers) showed more flight ability than T. juazeirensis despite having intermediate size wings. Furthermore, the presence of wings, as shown for T. infestans, does not necessarily account to flying capacity ${ }^{(4)}$. Nonetheless, this does not discard the wing metrics as a key element in flying performances ${ }^{(63)}$.

Habitat quality is one of the local conditions that might directly affect dispersal, by modifying the physiological condition of individuals or by producing changes in their phenotype ${ }^{(19)}$. The habitat dimensionality hypothesis states that habitats distributed at ground level can be reached by walking insects, whereas dispersal is more difficult without flight in three-dimensional habitats (with trees) ${ }^{(64)}$. The desert-like habitat of M. spinolai is mainly two-dimensional, and alary polymorphism is expected to occur. In this species, micropterous and macropterous individuals are mainly observed, with females always being micropterous allowing them to spend their energy mainly in reproduction ${ }^{(65)}$. Males could be either unwinged or winged; the latter disperse over longer distances ${ }^{(6)}$. Although flying $M$. spinolai are not usually captured, there are flight records under natural field conditions ${ }^{(67)}$; therefore, changes associated with its wing phenotype would be related to dispersal by flight.

The important role of antennal olfactory receptors during dispersal is well known. Although Moreno et al. ${ }^{(36)}$ have already observed and quantified intraspecific variation in the number and length of $\mathrm{TH}$, the combination of these two 
variables to estimate olfactory capacity allows a more accurate assessment of the role played by these sensory receptors and would allow the comparison among species. The OEC showed remarkable intraspecific differences between micropterous and macropterous individuals, even within the same sex, suggesting that this variation is not due to sexual dimorphism, but because of the ability to fly. Regarding the dispersal ability, multiporous sensilla would be particularly important. These olfactory receptors are capable of capturing odor molecules from considerable distances $^{(68)}$. In bloodsucking insects, a relationship was found between flight capacity and olfactory sensilla. Antennas lice, fleas, and bedbugs contain few olfactory receptors, unlike mosquitoes and other Diptera species that have significant ability to fly ${ }^{(69)(70)}$.

The sexual dimorphism in the OEC, even between micropterous males and females, indicates that TH receptors are also involved in the search of mates. The increased number of $\mathrm{TH}$ sensilla in males has been frequently observed in other species of Triatominae ${ }^{(25)(26)(28)(32)(71)}$. Insects use various strategies to expand their olfactory surface in order to increase contact with volatiles used for communication and orientation. In some hemimetabolous insects such as Ephemeroptera, Plecoptera, and Blattodea, the length of the antennae is increased to accommodate a greater number of olfactory sensilla ${ }^{(72)}$. In holometabolous insects, antennae also increase in size, but their shape is more sophisticated, allowing a greater exposure surface, such as feathery antennae in mosquitoes $^{(73)}$ and lepidopterans ${ }^{(74)}$. Another strategy to extend the olfactory surface is to increase the distal area of the antenna, such as in the case of capitate antennae of some hymenopterans and coleopterans $^{(75)}$. In Triatominae, no direct relationship has been found between the antenna length and sensilla number ${ }^{(76)}$, except during development. However, Catalá ${ }^{(32)}$ found that triatomines with a broad habitat range had more chemo-sensilla on the pedicel than species with a more restrictive habitat range. In Mepraia spp., the PTH length in macropterous males is the highest recorded for Triatominae ${ }^{(36)}$. Our results suggested that greater length of $\mathrm{TH}$ indicated greater olfactory surface, with a larger porous surface for exposure to compounds involved in chemical communication.

Our morphometric analyses indicated that the size, but not the shape, of the head in males did not vary with the presence/ absence of wings. Macropterous males showed less variability of head shape than micropterous males (lower metric disparity), which could suggest the importance of this variable in the flight processes. The head of an insect contains most of the sense organs, which allows it to interact with the environment; therefore, variability in head shape could be of great relevance in all activities, including flight. According to our comparisons, the ability to fly would be associated with a tighter shape of the head.

Both simple and compound eyes are known to influence the flight activities of insects in general ${ }^{(56)(77)(78)(79)(80)}$, and specifically in Triatominae ${ }^{(81)}$. The sensory information input in insects can occur in a composite and multimodal manner, combining the information from the eyes, ocelli, antennae, and cephalic sensilla, which translates into a composite signal used to control flight ${ }^{(82)}$. Compound eyes alone (that is, the ablation of ocelli) are capable of mediating visual stability of the head and the directionality behavior of flight under a wide range of conditions. Ocelli act synergistically with the eyes and increase the responses related to flight control ${ }^{(83)}$. Our results showed that the association between flight and compound eyes is due to the further development of the anterior portion of the eyes in macropterous individuals, which probably intervene in flight directionality (Figure 2).

The morphological changes found in M. spinolai could be used to determine differences in flight potential through morphological variables in other Triatominae species or subpopulations within the same species. In this study, only few insects available in the entomological collection were used for analysis. Although some samples might seem small, they can serve as a good indicator of the trends observed in the morphotypes. When analyzing natural populations (not reared in the laboratory), the sample size can be low even with high sampling effort. Schofield et al. ${ }^{(84)}$ collected very few adult M. spinolai after six years of sampling. Moreover, in studies of reinfestant Triatominae, low number of insects collected after an insecticide spray can also raise doubts about the technique used $^{(27)(85)}$. The results of these studies can provide evidence for further long-term studies, which might increase the number of insects collected and enhance the power of statistical tests.

For T. infestans, the main vector of T. cruzi in Latin America, sexual differences have been found in the flight dispersal activity. In La Rioja (Argentina), many male T. infestans showed differential allocation of food and sexual dimorphism in dispersion ${ }^{(86)}$.

The thorax of M. spinolai also showed an increase in size according to the development of the wings. These results are consistent with those reported for $T$. sherlocki, where its reduced wing size corresponded to less developed flight muscles and thorax size compared to that in T. juazeirensis, a closely related flying species ${ }^{(63)}$. Similarly, Hoffmann et al. ${ }^{(24)}$ found that, in Drosophila melanogaster, wing length and thorax size changed according to flight capacity.

Our results showed that macropterous $M$. spinolai have a larger olfactory surface, greater eye size, smaller anteocular distance of the head, and larger thorax size compared to those of micropterous specimens. The studied phenetic characteristics can serve as variables to determine differences in flight potential in this as well as other insect groups. Furthermore, they allow elucidation of the behavioral aspects related to insect dispersal and determination of how morphology accompanies behavioral alterations with changes in accordance to the requirements of insects in a particular environment. The identification of morphological characteristics associated with the presence/ absence of wings in insects is of major importance since it allows the determination of their dispersal potential. This is very useful, particularly in the case of insect disease vectors or crop pests, where the identification of dispersant morphotypes contributes to their efficient control.

\section{ACKNOWLEDGMENTS}

We thank Natalia Folguera for her assistance in laboratory work. 


\section{CONFLICT OF INTEREST}

The authors declare that there is no conflict of interest.

\section{FINANCIAL SUPPORT}

The work was funded by the Consejo Nacional de Investigaciones Científicas y Técnicas (CONICET, Argentina).

\section{REFERENCES}

1. Roff DA, Fairbairn DJ. Wing dimorphisms and the evolution of migratory polymorphisms among the Insecta. Am Zool 1991; 31: 243-251.

2. Wagner D, Liherr JK. Flightlessness in insects. Trends Ecol Evol 1992; 7: 216-220.

3. Denno RF. Tracking variable host plants in space and time. In: Denno RF, McClure MS, editors. Variable Plants and Herbivores in Natural and Managed Systems. New York: Academic; 1983. p. 291-341.

4. Harrison RG. Dispersal polymorphisms in insects. Annu Rev Ecol Evol Syst 1980; 11:95-118.

5. Roff DA. The evolution of wing dimorphism in insects. Evolution 1986; 40:1009-1020.

6. Zera AJ, Mole S. The physiological costs of flight capability in wing dimorphic crickets. Res Popul Ecol Kyoto 1994; 36:151-156.

7. Denno RF, Olmstead KL, McCloud ES. Reproductive cost of flight capability: a comparison of life history traits in wing dimorphic planthoppers. Ecol Entomol 1989; 14:31-44.

8. Schofield CJ. Triatominae - Biología y control. West Sussex, United Kingdom: Eurocommunica Publications; 1994. 80 p.

9. Campos R, Botto-Mahan C, Coronado X, Catalá SS, Solari A. Phylogenetic relationships of the Spinolai Complex and other Triatomini based on mitochondrial DNA Sequences (Hemiptera: Reduviidae). Vector Borne Zoonotic Dis 2013; 13:73-76.

10. Sagua H, Araya J, González J, Neira I. Mepraia spinolai in the Southeastern Pacific Ocean Coast (Chile) - First insular record and feeding pattern on the Pan de Azucar Island. Mem Inst Oswaldo Cruz 2000; 95:167-170

11. Lent H, Wygodzinsky P. Revision of Triatominae (Hemiptera, Reduviidae), and their significance as vector of Chagas disease. Bull Am Mus Nat Hist 1979; 163:1-520.

12. Bacigalupo A, Segura JA, Garcia A, Hidalgo J, Galuppo S, Cattan P. Primer hallazgo de vectores de la Enfermedad de Chagas asociados a matorrales silvestres en la Región Metropolitana, Chile. Rev Med Chile 2006; 134:1230-1236.

13. Lent H, Jurberg J. Algumas informações sôbre Triatoma spinolai Porter, 1934, com um estudo sôbre a genitálias externas (Hemiptera, Reduviidae, Triatominae). Rev Bras Entomol 1967; 27: 273-288.

14. Campos R, Botto-Mahan C, Coronado X, Jaramillo N, Panzera F, Solari A. Wing shape differentiation of Mepraia species (Hemiptera: Reduviidae). Infect Genet Evol 2011; 11:329-333.

15. Jaramillo N, Castillo D, Wolff EM. Geometric morphometric differences between Panstrongylus geniculatus from field and laboratory. Mem Inst Oswaldo Cruz 2002; 97:667-673.

16. Rodriguez Rodriguez J, Gonzalez O, Fraga J, Fidalgo LM, Dujardin JP. Morphometric changes of Triatoma flavida Neiva, 1911 (Hemiptera: Triatominae) in the transition from sylvatic to laboratory conditions. Rev Inst Med Trop Sao Paulo 2007; 49 127-130

17. Caro-Riaño H, Jaramillo N, Dujardin JP. Growth changes in Rhodnius pallescens under simulated domestic and sylvatic conditions. Infect Genet Evol 2009, 9:162-168.

18. Villacís AG, Grijalva MJ, Catalá SS. Phenotypic Variability of Rhodnius ecuadoriensis Populations at the Ecuadorian Central and Southern Andean Region. J Med Entomol 2010; 47:1034-1043.

19. Bernard MF, McCauley SJ. Integrating across life-history stages: consequences of natal abitat effects on dispersal. Am Nat 2008; 171:553-567.

20. Stamps JA. Habitat selection by dispersers: integrating proximate and ultimate approaches. In: Clobert J, Danchin E, Dhondt AA, Nichols JD, editors. Dispersal. Oxford: Oxford University Press; 2001. p. 230-242.

21. Clobert J, Le Galliard JF, Cote J, Meylan S, Massot M. Informed dispersal, heterogeneity in animal dispersal syndromes and the dynamics of spatially structured populations. Ecol Lett 2009; 12:197-209.

22. Dixon AF, Horth S, Kindlmann P. Migration in insects: cost and strategies. J Anim Ecol 1993; 62:182-190.

23. Braendle C, Davis GK, Brisson JA, Stern DL. Wing dimorphism in aphids. Heredity 2006; 97:192-199.

24. Hoffmann AA, Ratna E, Sgro CM, Barton M, Blacket M, Hallas $\mathrm{R}$, et al. Antagonistic selection between adult thorax and wing size in field released Drosophila melanogaster independent of thermal conditions. J Evol Biol 2007; 20:2219-2227.

25. Hernández ML, Abrahan L, Moreno M, Gorla DE, Catalá S. Phenotypic variability associated to genomic changes in the main vector of Chagas disease in southern cone of South America. Acta Trop 2008; 106:60-67.

26. Hernández ML, Abrahan L, Dujardin JP, Gorla DE, Catalá S. Phenotypic variability and population structure of peridomestic Triatoma infestans in rural areas of arid Chaco (western Argentina): spatial influence of macro and microhabitats. Vector Borne Zoonotic Dis 2011; 11:503-513.

27. Hernández ML, Dujardin JP, Gorla DE, Catalá SS. Potential sources of Triatoma infestans reinfesting peridomicilies identified by morphological characterization in Los Llanos, La Rioja, Argentina. Mem Inst Oswaldo Cruz 2013; 107:91-97.

28. Abrahan L, Hernández ML, Gorla DE, Catalá S. Phenotypic diversity of Triatoma infestans at the microgeographic level in the Gran Chaco of Argentina and Andean Valleys of Bolivia. J Med Entomol 2008; 45:660-666.

29. Schachter-Broide J, Dujardin JP, Kitron U, Gurtler R. Spatial structuring of Triatoma infestans (Hemiptera, Reduviidae) populations from northwestern Argentina using wing geometric morphometry. J Med Entomol 2004; 41:643- 649.

30. Catalá SS, Sachetto C, Moreno M, Rosales R, Salazar-Schettino PM, Gorla D. Antennal Phenotype of Triatoma dimidiata Populations and Its Relationship with Species of phyllosoma and protracta Complexes. J Med Entomol 2005; 42:719-725.

31. Bookstein F. Thin-plate splines and the atlas problem for biomedicalimages. In: Colchester ACF, Hawkes DJ, editors. Information processing in medical imaging. Wye: Springer-Verlag; 1991. p. 326-342.

32. Catalá SS. Antennal sensilla of triatominae (Hemiptera, Reduviidae): a comparative Study of five genera. Int J Insect Morphol 1997; 26:67-73.

33. Catalá S, Dujardin JP. Antennal Sensilla Patterns Indicate Geographic and Ecotopic Variability Among Triatoma infestans (Hemiptera: Reduviidae) Populations. J Med Entomol 2001; 38:423-428. 
34. Torres K, Avendaño F, Lizano E, Rojas M. Evaluación de la estructura espacial de Triatoma maculata del centro-occidente de Venezuela y su viabilidad alimentado con sangre humana en condiciones de laboratorio. Biomédica 2010; 30:72-81.

35. Gracco M, Catalá S. Inter-specific and developmental differences on the array of antennal chemoreceptors in four species of Triatominae (Hemiptera, Reduviidae). Mem Inst Oswaldo Cruz 2000; 95:67-74.

36. Moreno ML, Gorla DE, Catalá S. Association between antennal phenotype, wing polymorphism and sex in the genus Mepraia (Reduviidae: Triatominae). Infect Genet Evol 2006; 6:228-234.

37. Schofield CJ, Matthews JN. Theoretical approach to active dispersal and colonization of houses by Triatoma infestans. Am J Trop Med Hyg 1985; 88:211-222.

38. Schweigmann NJ, Vallve S, Muscio O, Ghillini M, Alberti A, Wisnivesky-Colli C. Dispersal fligth by Triatoma infestans in a arid area of Argentina. Med Vet Entomol 1988; 2:401-404.

39. Lehane MJ, Schofield CJ. Flight initiation in Triatoma infestans (Klug) (Hemiptera, Reduviidae). Bull Entomol Res 1982; 72:497510.

40. Lehane MJ, McEwen PK, Whitaker CJ, Schofield CJ. The role of temperature and nutritional status in flight initiation by Triatoma infestans. Acta Trop 1992; 52:27-38.

41. Schofield CJ. Control of Chagas disease vectors. Br Med Bull 1985; 41:187-194.

42. Ceballos LA, Vazquez-Prokopec GM, Cecere MC, Marcet PL, Gürtler RE. Feeding rates, nutritional status and flight dispersal potential of peridomestic populations of Triatoma infestans in rural northwestern Argentina. Acta Trop 2005; 95:149-159.

43. Vazquez-Prokopec G, Ceballos L, Kitron U, Gurtler R. Active Dispersal of Natural Populations of Triatoma infestans (Hemiptera: Reduviidae) in Rural Northwestern Argentina. J Med Entomol 2004; 41:614-621.

44. Gurevitz JM, Ceballos LA, Kitron U, Gürtler RE. Flight initiation of Triatoma infestans (Hemiptera: Reduviidae) under natural climatic conditions. J Med Entomol 2006; 43:143-150.

45. Gurevitz JM, Kitron U, Gürtler RE. Flight muscle dimorphism and heterogeneity in flight initiation of field-collected Triatoma infestans (Hemiptera: Reduviidae). J Med Entomol 2007; 44: 186-191.

46. Soares RP. Aspectos Biológicos, Bioquímicos e Morfológicos Relacionados a Atividades de Vôo das Principais Espécies Vetoras da Doença de Chagas no Brasil. 1997. 94p. (Master's Thesis). Universidade Federal de Minas Gerais; 1997 Belo Horizonte.

47. Gurevitz JM, Kitron U, Gürtler RE. Temporal dynamics of flight muscle development in Triatoma infestans (Hemiptera: Reduviidae). J Med Entomol 2009; 46:1021-1024.

48. Hernández ML. Efecto del tratamiento con insecticidas sobre la estructuración de Triatoma infestans en distintos hábitats de los Llanos de La Rioja. 2012. 154 p. (Doctor's Thesis). Universidad Nacional de Córdoba; 2012 Argentina.

49. Botto-Mahan C. Modificación fenotípica inducida por parásitos: la interacción Mepraia spinolai-Trypanosoma cruzi. 2004. 102 p. (PhD Thesis). Universidad de Chile; 2004 Santiago.

50. Rohlf FJ. Shape statistics: Procrustes superimpositions and tangent spaces. J Classif 1999; 16:197-223.

51. Zelditch ML, Swiderski DL, Sheets HD, Fink WL. Geometric morphometrics for biologist: A primer. San Diego: Elsevier Academic Pres; 2004.

52. Wigglesworth VB, Gillett JD. The function of the antennae in Rhodnius prolixus (Hemiptera) and the mechanism of orientation to the host. J Exp Biol 1934; 11:120-139.
53. Dujardin JP. Collecting Landmaks for Identification and Caracterization (CLIC) (Software Internet). Version 97. Institut de Recherche pour le Dévelopment (IRD); Available at http://momeclic.com

54. Klingenberg Lab. Morpho J (Software Internet). Version 1.05f. Manchester: The University of Manchester. Available at http:// www.flywings.org.uk/MorphoJ_page.htm

55. StatSoft Inc. STATISTICA (CD ROM). Version 7.1. USA; 2005.

56. Kalmus H. Correlations between flight and vision, and particulary between wings and ocelli, in insects. Proc R Soc Lond 1945; 20:84-96.

57. Kring JB. Sructure of the eyes of the pea aphid, Acyrthosiphon pisum. Ann Entomol Soc Am 1977; 70: 855-860.

58. Kawada K. Polimorphism and morph determination. In: Minks AK, Harrewijn P, editors. Aphids, Their Biology, Natural Enemies and Control. Amsterdam: Elsevier; 1987. p. 255-266.

59. Tsuji H, Kawada K. Development and degeneration of wing buds and indirect flight muscles in the pea aphid (Acyrtosiphon pisum (Harris). Jpn J Appl Entomol Zool 1987; 31:247-252.

60. Hazell SP, Gwynn DM, Ceccarelli S, Fellowes MD. Competition and dispersal in the pea aphid: clonal variation and correlations across traits. Ecol Entomol 2005; 30:293-298.

61. Moore JC, Loggenberg A, Greeff JM. Kin competition promotes dispersal in a male pollinating fig wasp. Biol Lett 2006; 2:17-19.

62. Merckx T, Van Dyck H. Landscape structure and phenotypic plasticity in flight morphology in the butterfly Pararge aegeria. Oikos 2006; 113:226-232.

63. Almeida CE, Oliveira HL, Correia N, Dornak LL, Gumiel M, Neiva VL, et al. Dispersion capacity of Triatoma sherlocki, Triatoma juazeirensis and laboratory-bred hybrids. Acta Trop 2012; 122:71-79.

64. Roff DA. The evolution of flightlessness in insects. Ecol Monogr 1990; 60: 389-421.

65. Puchkova LV. Functions of the wings in the Hemiptera and trends in their specialization. Entomol Rev 1971; 50: 303-309.

66. Solbreck C. Wing and flight muscle polymorphism in a lygaeid bug, Horvathiolus gibbicollis: determinants and life history consequences. Ecol Entomol 1986; 11:435-444.

67. Bacigalupo A, Arroyo P, Hernández J, Cattan P. First capture of dispersal adults of Triatoma infestans and Mepraia spinolai by black light traps from sylvatic foci of Chile. In: International Workshop on Chagas Disease, triatomine vectors, Trypanosoma cruzi, and Triatoma virus. Cochabamba, Bolivia, 2012; 57p.

68. Steinbrecht RA. Odorant-Binding Proteins: Expression and Function. Ann N Y Acad Sci 1998; 855:323-332.

69. Chapman RF. Evolution of insect chemosensory systems and food selection behaviour. In: van-der Starre $\mathrm{H}$, editor. Olfaction and Taste. Vol. VII. London: Information Retrieval; 1980. p. 131-133.

70. Mc Iver S. Sensilla of haematophagous insects sensitive to vertebrate host-associated stimuli. Insect Sci Appl 1987; 8:627-635.

71. Arroyo CM, Esteban L, Catalá S, Angulo VM. Variación del fenotipo antenal de poblaciones del domicilio, peridomicilio y silvestres de Triatoma dimidiata (Hemiptera, Reduviidae) en Santander, Colombia. Biomédica 2007; 27:92-100.

72. Schaller D. Antennal sensory system of Periplaneta americana L.: distribution and frequency of morphologic types of sensilla and their sex-specific changes during postembryonic development. Cell Tissue Res 1978; 191:121-139.

73. Schneider D. Insect Antennae. Annu Rev Entomol 1964; 9: 103-122.

74. Hansson BS. Olfaction in Lepidoptera. Experientia 1995; 51: 1003-1027. 
75. Keill TA. Morphology and Development of the Peripheral olfactory organs. In: Hansson B, editor. Insect olfaction. New York: Springer, Berlin Heidelberg; 1999. p. 5-47.

76. Carbajal-de-la-Fuente AL, Catalá S. Relationship between antennal sensilla pattern and habitat in six species of Triatominae. Mem Inst Oswaldo Cruz 2002; 97:1121-1125.

77. Moser JC, Reeve JD, Bento JM, Lucia TM, Cameron RS, et al. Eye size and behaviour of day- and night-flying leafcutting ant alates. J Zool 2004; 264:69-75.

78. Stange G, Howard J. An ocellar dorsal light response in dragonfly. J Exp Biol 1979; 83:351-355.

79. Stange G. The ocellar component of Fligth equilibrium control in dragonflies. J Comp Physiol 1981; 141:335-347.

80. Rowell CH, Pearson KG. Ocellar input to the flight motor system of the locust: structure and function. J Exp Biol 1983; 103:265-288.

81. Lazzari CR, Reiseman CE, Insausti TC. The role of the ocelli in the phototactic behaviour of the haematophagous bug Triatoma infestans. J Insect Physiol 1998; 44:1159-1162.
82. Taylor GK, Krapp HG. Sensory systems and flight stability: what do insects measure and why? Adv Insect Physiol 2007; 34:231-316.

83. Taylor CP. Contribution of compound eyes and ocelli to steering of locusts in flight: I. Behavioural analysis. J Exp Biol 1981; 93:1-18.

84. Schofield CJ, Apt W, Sagua H, Panzera F, Dujardin JP. Alary polymorphism in Triatoma spinolai and its possible relationship with demographic strategy. Med Vet Entomol 1998; 12:30-38.

85. Gaspe MS, Gurevitz JM, Gürtler RE, Dujardin JP. Origins of house reinfestation with Triatoma infestans after insecticide spraying in the Argentine Chaco using wing geometric morphometry. Infect Genet Evol 2013; 17:93-100.

86. Abrahan LB, Gorla D, Catalá S. Dispersal of Triatoma infestans and other Triatominae species in the arid Chaco of Argentina: Flying, walking or passive carriage? The importance of walking females. Mem Inst Oswaldo Cruz 2011; 106:232-239. 